\title{
60 лет на службе науке... (посвящается 80-летию д.г.н., проф. В.А. Брылева)
}

\author{
И.С. Дедова ${ }^{\bowtie}$ Т. Н. Буруль, Н. П. Дьяченко \\ Волгоградский государственный соџиально-педагогический университет, Российская Федераџия \\ (400066, г. Волгоград, пр. им. В. И. Ленина, 27)
}

\begin{abstract}
Аннотация: В статье приводятся сведения о научном и творческом пути доктора географических наук, профессора ВГСПУ В.А. Брылева. Анализируется ранний этап его научной деятельности, приводятся данные по научному геоморфологическому и геоэкологическому наследию. Отмечена первостепенная роль В. А. Брылева в формировании Волгоградской научной геоморфологической школы, а также в развитии региональной геоэкологии Нижнего Поволжья.
\end{abstract}

Ключевые слова: Виктор Андреевич Брылев, биография, диссертация, геоморфология, геоэкология, научная школа.

Для цитирования: Дедова И.С., Буруль Т. Н., Дьяченко Н. П. 60 лет на службе науке... (посвящается 80-летию д.г.н., проф. В. А. Брылева) // Вестник Воронежского государственного университета. Серия География. Геоэкология, 2020, № 4, с. 94-100. DOI: https://doi.org/10.17308/geo.2020.4/3070

\section{ВВЕДЕНИЕ}

6 мая 2020 года исполнилось 80 лет со дня рождения доктора географических наук, профессора, главного научного сотрудника Волгоградского государственного социально-педагогического университета, члена редакционной коллегии журнала «Геоморфология» Виктора Андреевича Брылева.

В.А. Брылев - ученый - геоморфолог, методист, педагог, создавший за многие годы своей научно-педагогической деятельности школу геоморфологов и геоэкологов - исследователей территории Волгоградского Поволжья. Ему принадлежат более 590 публикаций, среди которых шесть монографий, многочисленные статьи, включенные в международные системы цитирований, учебные и учебно-методические пособия, четыре поколения географических Атласов Волгоградской области, задепонированы Медико-географический атлас Волгоградской области и другие картографические произведения. Под его руководством защищено три докторских и 22 кандидатские диссертации в ученых советах Москвы, Казани, Воронежа, Ростова-на-Дону, Краснодара.

Виктор Андреевич Брылев принадлежит к числу тех ученых, которые осознали свое научное при- звание со студенческих лет. В 1958 году студентом-первокурсником он начинает учебу на географическом факультете Казанского государственного университета. Со студенческой скамьи, с формированием интереса к уникальному рельефу Казанского Поволжья, его генезису и развитию под влиянием выдающихся ученых университета начиналось научное творчество профессора В. А. Брылева как геоморфолога. Студентом Виктором Брылевым были защищены курсовая и дипломная работы, посвященные генетическому анализу речных долин Среднего Урала по данным полевых исследований под руководством известнейшего карстоведа, заведующего кафедрой физической географии КГУ профессора Ступишина А. В.

\section{МЕТОДИКА РАБОТЫ}

Геоморфологическое научное будущее Виктора Андреевича было окончательно определено в 1963 году, когда под влиянием проф. А. В. Ступишина и проф. А. П. Дедкова В. А. Брылев переезжает в город Волгоград. Он тут же поступает на должность инженера во вновь открывшуюся лабораторию геоморфологии и неотектоники Нижневолжского отделения Всесоюзного научно-исследовательского института нефтяной и газовой

(ㄱ Дедова И.С., Буруль Т.Н., Дьяченко Н.П., 2020

$\triangle$ Дедова Ирина Сергеевна, e-mail: itrofimova@yandex.ru

Контент доступен под лицензией Creative Commons Attribution 4.0 License. 
промышленности под руководством доктора географических наук, профессора А.В. Цыганкова, который был весьма заинтересован в молодом и талантливом ученом. В лаборатории он проработает 8 лет, перейдя на должность младшего, а потом и старшего научного сотрудника.

Под руководством профессора А. В. Цыганкова Виктор Андреевич в течение полевых сезонов принимал активное участие в обширных по охвату территории геоморфологических изысканиях Нижнего Поволжья. Целью этого масштабного исследования был детальный морфоструктурный анализ, а также обоснование роли неотектоники в оформлении структурного плана территории. Результаты экспедиций позволили создать представление о морфоструктуре Нижнего Поволжья, оценить первостепенную роль неотектоники в оформлении крупных форм рельефа, а также проанализировать интенсивность денудации и генезис морфоскульптурных комплексов. Впервые открытые закономерности развития и строения рельефа Нижнего Поволжья стали основой в работе над двумя монографиями: «Геология СССР» (том 46, раздел «Геоморфология», 1970 г.) и «Методика изучения неотектоники и морфоструктура Нижнего Поволжья», 1971 г. [7, 8].

В 1968 году Виктор Андреевич защищает кандидатскую диссертацию в г. Ростове-на-Дону. Тема ее исследования касалась спорных вопросов палеогеоморфологии и неотектоники Волгоградского Поволжья. В своей работе молодой ученый впервые для нашего региона рассмотрел вопросы, касающиеся структурного плана Волгоградской области, его оформления под влиянием неотектоники, а также экзогенных процессов.

В 1971 году В.А. Брылев был приглашен на должность старшего преподавателя кафедры физической географии Волгоградского государственного педагогического института. В 1975 году Виктор Андреевич уже в должности доцента возглавил кафедру, став ее бессменным заведующим на 44 года. Именно руководство научно-педагогическим коллективом кафедры позволит ему сгенерировать ряд важнейших научных направлений в изучении природы Волгоградской области, уделяя первостепенное внимание геоморфологическим и геоэкологическим исследованиям.

Новые административные обязанности не снизили активности научной работы доцента В. А. Брылева. В течение последующих 15 лет им были апробированы геоморфологические методики А. В. Цыганкова, С. К. Горелова, Д. А. Тимофе- ева, В. И. Галицкого и других ученых. Обработаны результаты многочисленных научных экспедиций по Волгоградской области, детализированы данные по геологическому строению региона, представленные материалами более 1000 скважин геологоразведочного бурения. Итогом этой кропотливой работы стала докторская диссертация на тему «Этапность и цикличность морфогенеза платформенных равнин», успешно защищенная в лаборатории геоморфологии Института Географии AH CCCP.

Концептуальный подход в решении задач, сформированных в диссертации, был принципиально новым в науке. Впервые, на примере региональной геоморфологии юго-востока Русской равнины был опровергнут ставший аксиомой постулат об интенсивности неотектонических движений и их роли в формировании современного геоморфологического плана Нижнего Поволжья. Количественные показатели неотектонических движений и скорости денудационного среза были обоснованы еще в 60-е годы XX века в трудах А. В. Цыганкова и «привязаны» к неоген-четвертичному этапу развития земной коры. В.А. Брылевым в диссертационном исследовании был обоснован более древний олигоцен-четвертичный возраст оформления структурного плана территории исследования, в результате чего количественные показатели интенсивности денудации были скорректированы под новые хронологические рамки. Это утверждение вызвало живую полемику не только среди отечественных геоморфологов, но и их зарубежных коллег. Сама трактовка неотектонического этапа развития земной коры подразумевала именно оформление структурного плана конкретной территории, и, следовательно, возраст мог выходить за рамки неоген-квартера.

Весьма оригинален подход, предложенный Виктором Андреевичем в сравнительном геоморфологическом анализе территорий-аналогов перикратонного оформления, позже отраженный в его монографии «Эволюционная геоморфология юго-востока Русской равнины» (2006 г.) [1]. Им впервые была выполнена сравнительная палеогеоморфологическая характеристика юго-востока Русской равнины, Мидконтинента Северной Америки, Чешского массива Средней Европы, что позволило выявить черты сходства и отличия в развитии рельефа этих территорий, связав установленные закономерности с эволюцией планетарного рельефа. 
В докторской диссертации Виктора Андреевича оказался разрешенным вопрос о геоморфологической преемственности древних долин. Еще со времен М.И. Грищенко и Ю. А. Петроковича (3040-е гг. ХХ в) считалось, что крупные речные системы прошлого (Ламкинско-гуровская миоценовая река и плиоценовая Ергень-река) были унаследованы Палео-Волгой как титульной речной системой еще в раннем плейстоцене. Реконструкция неоген-плейстоценовых ландшафтов Нижнего Поволжья по данным геологического бурения и палеонтологического анализа позволила В. А. Брылеву обосновать генетическую связь между Ергень-рекой и Палео-Доном. Это поставило точку в многолетних суждениях об исчезновении загадочных рек прошлого, доказало былую многоводность Палео-Дона, объяснило причины перехватов и перестройки речной сети, связь глубины эрозионных врезов погребенных долин с колебаниями уровня Понто-Каспия.

Итоги плодотворных многолетних научных изысканий В.А. Брылевым были дополнены уже в 1990-2000-е годы новыми данными об антропогенной трансформации рельефа, а в 2006 году вышла в свет монография «Эволюционная геоморфология юго-востока Русской равнины», являющаяся одним из основополагающих научных произведений по палеогеоморфологии и методологии выделения геоморфологических этапов в развитии конкретной территории. В монографии Виктор Андреевич в очередной раз доказывает гипотезу о направленности и цикличности как важнейших закономерностях развития рельефа Земли, переводя ее в ранг научного постулата. Им обосновывается выделение особого «геоморфологического этапа» в истории Земли, как промежутка времени, охватывающего мезозой - настоящее время. Весьма интересна и территория исследования, выбранная им для обоснования научных фактов, представленная сочетанием разновозрастных структур и несущая следы геологических событий на Урале, Донбассе и Кавказе.

Впервые для Нижнего Поволжья выделяется особый антропогенно-техногенный этап эволюции рельефа, приводятся количественные показатели техногенной денудации, оцениваются положительные и отрицательные воздействия человека на геосреду. Рассмотрение его наряду с другими геоморфологическим циклами проводится Виктором Андреевичем без отрыва от литогенной основы, что и дает ему возможность определить темпы рельефообразующей роли деятельности человека и спрогнозировать дальнейшее изменение рельефа.

В. А. Брылев, как истинный геоморфолог, всегда в своих разносторонних научных исследованиях (а они имели и ландшафтную, и физико-географическую, и геоэкологическую направленность) оценивал рельеф как средоформирующий компонент, литогенную основу любого ландшафта, которая определяет не только потоки вещества и энергии, но и временную и пространственную изменчивость геосистем. В своих работах он всегда подчеркивал, что невозможно изучать природные процессы без знаний о геологическом строении территории и ее рельефе. Поэтому в проектных работах по обоснованию многочисленных особо охраняемых природных территорий Волгоградской области (ООПТ) большое внимание было уделено такому критерию, как рельеф, его уникальность, реликтовость, эстетическая привлекательность форм, сохранность [4]. Благодаря стараниям Виктора Андреевича на территории Волгоградской области были утверждены геолого-геоморфологические памятники природы, созданы природные парки, заказники, и для каждой категории ООПТ рельеф выступал как один из важных факторов заповедывания. Для Донского природного парка Брылевым В.А. и его сотрудниками были описаны реликтовые формы плиоценовых педиментов, для Щербаковского - ярусный рельеф; Цимлянского - эоловые экзотические формы на площади флювиогляциальных песков надпойменных террас Дона [9].

Подобное отношение к рельефу как к геоморфологическому «зеркалу» ландшафта или геосистемы, В. А. Брылев сумел привить и своим ученикам. Несмотря на свою рабочую занятость и активную научную жизнь, значительное количество выступлений на Пленумах Геоморфологической Комиссии РАН, Межвузовских Координационных совещаниях по проблемам эрозионных, русловых и устьевых процессов, региональных, всероссийских и международных конференциях эколого-геоморфологической направленности, он всегда находил время для консультаций, научного наставничества, организации экспедиций своих аспирантов и соискателей. Начиная с 1990-х годов, складывается местная научная школа геоморфологов в Волгоградском государственном педагогическом институте (ныне ВГСПУ) под руководством профессора, доктора географических наук В. А. Брылева. 
Благодаря организаторскому таланту и высокому профессионализму В. А. Брылева, его научной увлеченности, умении сплотить вокруг себя и повести за собой коллег и творческую молодежь, развивается признанная на международном уровне Волгоградская геоморфологическая школа, главными направлениями исследований которой стали проблемы палеогеоморфологии, морфодинамики, экзогенной, экологической и антропогенной геоморфологии. Многочисленные научные наработки и идеи геоморфологического характера были реализованы и воплощены в жизнь в диссертациях учеников Виктора Андреевича, опирающихся на местные полевые изыскания и решающих задачи региональной геоморфологии.

Под руководством В. А. Брылева аспирантами и соискателями были проведены такие геоморфологические исследования на территории Волгоградского Поволжья, которые позволили апробировать новые научные методики исследования, создать геоинформационную базу в изучении рельефа Нижнего Поволжья, уточнить полученные ранее сведения о генезисе отдельных форм и типов рельефа. Еще в 1990-е годы был выполнен эколого-геоморфологический анализ экзоморфогенеза по материалам дешифрирования космической фотосъемки; определены географические закономерности современной дефляции в степях ВосточноЕвропейской равнины, а также рассмотрены региональные особенности техноморфогенеза при различных видах хозяйственной деятельности. В начале 2000-х годов вновь актуализировались исследования по оценке эволюции береговой зоны Волгоградского водохранилища в современных условиях зарегулирования Волги. На основе данных геологоразведки была реконструирована и палеогидросеть палеозоя Волгоградской области и произведена ее оценка на нефте- и газоносность. В последствии научным вниманием были затронуты как природные процессы рельефообразования (выделены этапы формирования больших коренных излучин Волги и Дона и выполнен пространственный анализ эрозионных систем в их пределах), так и антропогенные (особенности развития и современного состояния открытых горных выработок, как крупных форм горнотехнического рельефа). В 2011-2014 годы были осуществлены пространственно-временной анализ древнего и современного морфогенеза Волго-Донского междуречья, начиная с ранних этапов хозяйственного освоения; оценка геоморфологической устойчивости оползнеопасных склонов Волгоградского По- волжья; структурно-геоморфологический и геоэкологический анализ малых и средних речных бассейнов Волгоградского Правобережья.

Благодаря организаторскому таланту В. А. Брылева в Волгограде на базе возглавляемой им кафедры дважды были проведены Пленумы Геоморфологической комиссии Института Географии РАН - в 1996 году по проблемам специализированного геоморфологического картографирования и в 2014 году по результатам исследований экзогенных рельефообразующих процессов. Неоднократно, начиная с 2000 года кафедра, возглавляемая Виктором Андреевичем, являлась научной базой для организации Межвузовских координационных совещаний по проблемам эрозионных, русловых и устьевых процессов под руководством профессора МГУ, д.г.н. Р. С. Чалова.

Результаты геоморфологических исследований Волгоградского Поволжья находят отражение в изданиях различного уровня - журнале «Геоморфология», материалах научных конференций различного уровня, а также в коллективных монографиях - «Волгоградская область: природные условия, ресурсы, хозяйство, население, геоэкологическое состояние» (2011) [6], «Геоморфология Волгоградской области» (2017) [3].

Начиная с 70-80-х годов XX века в региональной географии формируется экологическая составляющая научных исследований. Впоследствии симбиоз классической географии с принципиально новым дисциплинарным направлением позволит сформировать цели и задачи инновационной науки - региональной геоэкологии. И по прошествии уже 40 лет ее активного развития можно смело утверждать, что основы природоцентрического подхода в географии Нижнего Поволжья были заложены именно В. А. Брылевым. Одной из первых работ этого направления стало изучение влияния антропогенных факторов на природные комплексы и экосистемы Волго-Ахтубинской поймы. В рамках этого полномасштабного проекта Виктор Андреевич будет трудиться с 1975 года по настоящее время. Закономерными итогами проведенных исследований станут данные по трансформации ландшафтов Волго-Ахтубинской поймы в условиях сокращения стока реки Волга, степени деградации пойменных лесов, сокращению биоразнообразия, а также разработанные меры по охране и рекультивации уникальных и сохранных ПТК, которые станут основой создания первого в Волгоградской области природного парка - Волго-Ахтубинского (1999 г.) [97]. Интерес к геоэкологи- 
ческим проблемам и особенностям охраны природы поймы В. А. Брылев активно проявляет и сегодня, затрагивая столь болезненную для нашего региона тему выступлениями на научных семинарах и конференциях различного уровня, а также в средствах массовой информации [2].

Еще с 80-х годов XX века Виктор Андреевич принимает активное участие в подготовке научного издания «Антропогенные воздействия на экосистемы и их компоненты» (1982), а также «Природа и хозяйственная деятельность в Нижнем Поволжье» $(1986,1988)$, обосновывает отрицательные последствия строительства судоходного канала «Волга-Дон-2» и ирригационной системы «ВолгаЧограй» для природных комплексов сухостепной зоны. В то же время им нарабатывается обширный материал по итогам участия в масштабной научной программе по изучению почвенно-экологических и мелиоративных особенностей юга России, связанных с переброской части стока северных и сибирских рек.

Наконец, именно в 80-е годы XX века В. А. Брылевым формируется мощная теоретическая база по развитию экологического и природоохранного каркаса Нижнего Поволжья. Работая в качестве эксперта Всесоюзного общества охраны природы, Виктор Андреевич реализует в практику научные идеи по формированию сети памятников природы, статуированию заказников, наконец, разрабатывает концептуальную основу формирования ООПТ высокого ранга - природных и национальных парков.

Активная эволюция идей в региональной геоэкологии позволила Виктору Андреевичу сплотить научный круг молодых специалистов-геоэкологов, определить приоритетные направления региональных геоэкологических исследований, касаемых не только Нижнего Поволжья, но и сопредельных территорий, развить новое направление - региональное геоэкологическое картографирование [5]. На кафедре ВГПУ успешно функционирует лаборатория геоэкологии и ландшафтоведения, где формируется та геоэкологическая информационная платформа, которая станет основой защищенных кандидатских диссертаций 12-ти его учеников. С конца 1990-х годов кафедра физической географии, которой руководит В.А. Брылев, будет переименована в кафедру физической географии и геоэкологии, справедливо отдавая дань тому, что геоэкологические исследования сотрудников и их руководителя носят все более масштабный характер. С 1994 года при кафедре функционирует ас- пирантура по научной специальности 11.00.11 «Охрана окружающей среды и рациональное использование природных ресурсов», а с 2001 года 25.00 .36 «Геоэкология». Исследования аспирантов и соискателей, выполненные с 90-х годов до настоящего времени, позволили охватить все пространственно-временные аспекты взаимодействия человека и природы в Нижнем Поволжье, установить закономерности эволюции геосреды под влиянием антропогенных факторов, реализовать приоритетные направления в совершенствовании сети ООПТ Нижнего Поволжья. В 1997 году Виктор Андреевич принимает участие в Международном симпозиуме «Особо охраняемые территории и формирование здорового образа жизни», с начала 90-х годов является председателем секции Поволжских экологических Чтений, ежегодно проходивших на базе Нижневолжского отделения Российской экологической академии, почетным членом которой является. Многочисленные статьи, выступления на конференциях разного уровня, работа по совершенствованию ООПТ Волгоградской области, карты антропогенной нагрузки, геоэкологических ситуаций Волгоградской области, учебные пособия для ВУЗов и школ - вот та малая часть огромного научного наследия по геоэкологии, которое воплотил в жизнь Виктор Андреевич!...

\section{ЗАКЛЮЧЕНИЕ}

Виктор Андреевич с энтузиазмом и воодушевлением продолжает служить любимому делу - науке. Он полон научных идей, активно сочетает разностороннюю деятельность с передачей своего бесценного научно-методического опыта подрастающим поколениям студентов, магистрантов, молодых ученых... Его любимые направления научного поиска - геоморфология и геоэкология до сих пор плодотворно пополняются новыми научными публикациями, выступлениями, достижениями профессора В. А. Брылева. Мы желаем Виктору Андреевичу долгих лет активной научной деятельности, крепкого здоровья и дальнейших творческих успехов!

\section{СПИСОК ЛИТЕРАТУРЫ}

1. Брылев В. А. Эволюиционная геоморфология юговостока Русской равниныл. Волгоград, Перемена, 2006. $350 \mathrm{c}$.

2. Брылев В.А., Буруль Т.Н., Пряхин С. И., Дедова И. С., Семикин Д. В., Мелихова Е. В., Овчарова А. Ю., Корхова Ю.А. Антропогенные воздействия на гидросферу Приволгоградской части Волго-Ахтубинской поймы // Альманах - 2013 / под ред. Г.К. Лобачевой. Волгоград, Изд-во ВолГУ, 2013, с. 22-36. 
3. Брылев В.А., Дедова И. С., Дьяченко Н.П., Мелихова Е. В., Голикова Ю.А. Геоморфология Волгоградской области. Москва, Издательство «Планета», 2017. $224 \mathrm{c}$.

4. Брылев В.А., Сагалев В.А. Особо охраняемые природные территории. Волгоград, Перемена, 2000. $260 \mathrm{c}$.

5. Брылев В. А., Сергиенко Н. В., Клюшникова Н. М. Среднемасштабное экологическое картографирование. Волгоград, Перемена, 2007. 105 с.

6. Волгоградская область: природные условия, ресурсы, хозяйство, население, геоэкологическое состо- яние / под ред В. А. Брылева. Волгоград, Перемена, 2011. $495 \mathrm{c}$.

7. Геология СССР. T. 46. / под ред. А. В. Белова. Москва, Недра, 1970. 667 с.

8. Методика изучения неотектоники и морфоструктура Нижнего Поволжья / под ред. А. В. Цыганкова. Волгоград, Нижне-Волж. кн. изд-во, 1971. 255 с.

9. Особо охраняемые природные территории Волгоградской области / под ред. В.А. Брылева. Волгоград, Альянс, 2006. 256 с.

Конфликт интересов: Авторы декларируют отсутствие явных и потенциальных конфликтов интересов, связанных с публикацией настоящей статьи.

Поступила в редакиию 22.12.2019

Принята к публикачии 20.11.2020

\title{
60 Years in the Service of Science... (Dedicated to the 80th Anniversary of Dr. of Geography, Professor Victor A. Brylev)
}

\author{
I.S. Dedova网, T. N. Burul, N.P. Dyachencko \\ Volgograd State Social and Pedagogical University, Russian Federation \\ (27, V.I. Lenin Ave., Volgograd, 400066)
}

\begin{abstract}
The article provides information about the scientific and creative path of doctor of geographical sciences, professor V. A. Brylev. The early stage of its scientific activity is analyzed, data on scientific geomorphological and geoecological heritage are given. The primary role of V. A. Brylev in the formation of the Volgograd scientific geomorphological school, as well as in the development of regional geoecology of the Lower Volga region is noted.

Key words: Victor Andreevich Brylev, biography, dissertation, geomorphology, geoecology, scientific school.

For citation: Dedova I. S., Burul T. N., Dyachencko N.P. 60 years in the service of science... (dedicated to the 80th anniversary of Dr. of Geography, professor Victor A. Brylev). Vestnik Voronezskogo gosudarstvennogo universiteta. Seria Geografia. Geoekologia, 2020, No. 4, pp. 94-100. (In Russ.) DOI: https://doi.org/10.17308/geo.2020.4/3070
\end{abstract}

\section{REFERENCES}

1. Brylev V. A. Evolyutsionnaya geomorfologiya yugovostoka Russkoy ravniny [Evolutionary geomorphology of the southeast of the Russian Plain]. Volgograd, Publ. Peremena, 2006. 350 p. (In Russ.)

2. Brylev V. A., Burul' T. N., Pryakhin S. I., Dedova I. S., Semikin D. V., Melikhova E. V., Ovcharova A. Yu., Korkhova Yu. A. Antropogennye vozdeystviya na gidrosferu Privol-

(C) Dedova I. S., Burul T.N., Dyachencko N.P., 2020

\Irina S. Dedova, e-mail: itrofimova@yandex.ru gogradskoy chasti Volgo-Akhtubinskoy poymy. Al'manakh -2013 [Anthropogenic impacts on the hydrosphere of the Volgograd part of the Volga-Akhtubinskaya floodplain. Almanakh - 2013] ed. G.K. Lobacheva. Volgograd, VolGU Publ. House, 2013, pp. 22-36. (In Russ.)

3. Brylev V.A., Dedova I.S., D'yachenko N.P., Melikhova E. V., Golikova Yu. A. Geomorfologiya Volgogradskoy oblasti [Geomorphology of the Volgograd Region]. Moscow, "Planeta" Publ. House, 2017. 224 p. (In Russ.)

The content is available under Creative Commons Attribution 4.0 License. 
4. Brylev V. A., Sagalev V.A. Osobo okhranyaemye prirodnye territorii [Specially protected natural areas]. Volgograd, Publ. Peremena, 2000. 260 p. (In Russ.)

5. Brylev V.A., Sergienko N. V., Klyushnikova N. M. Srednemasshtabnoe ekologicheskoe kartografirovanie [Medium-scale environmental mapping]. Volgograd, Publ. Peremena, 2007. 105 p. (In Russ.)

6. Volgogradskaya oblast': prirodnye usloviya, resursy, khozyaystvo, naselenie, geoekologicheskoe sostoyanie [Volgograd region: natural conditions, resources, economy, population, geoecological state] ed. V. A. Brylev. Volgograd, Publ. Peremena, 2011. 495 p. (In Russ.)

7. Geologiya SSSR. T. 46. [Geology of the USSR. V. 46] ed. A. V. Belova. Moscow, Publ. Nedra, 1970. 667 p. (In Russ.)

\section{Дедова Ирина Сергеевна}

кандидат географических наук, доцент кафедры географии, геоэкологии и методики преподавания географии Волгоградского государственного социально-педагогического университета, г. Волгоград, Российская Федерация, ORCID: https://orcid.org/0000-0002-2768-9421, e-mail: itrofimova@yandex.ru

Буруль Татьяна Николаевна кандидат географических наук, доцент кафедры географии, геоэкологии и методики преподавания географии Волгоградского государственного социально-педагогического университета, г. Волгоград, Российская Федерация, ORCID: https://orcid.org/0000-0002-6750-3919, e-mail: busmit@mail.ru

Дьяченко Надежда Петровна

кандидат географических наук, доцент кафедры географии, геоэкологии и методики преподавания географии Волгоградского государственного социально-педагогического университета, г. Волгоград, Российская Федерация, ORCID: https://orcid.org/0000-0002-9576-0250, e-mail: ms.npdyachenko@mail.ru
8. Metodika izucheniya neotektoniki i morfostruktura Nizhnego Povolzh'ya [Methods for studying neotectonics and morphostructure of the Lower Volga region] ed. A. V. Tsygankova. Volgograd, Nizhne-Volzh. Book Publ. House, 1971. 255 p. (In Russ.)

9. Osobo okhranyaemye prirodnye territorii Volgogradskoy oblasti [Specially protected natural territories of the Volgograd region] ed. V. A. Bryleva. Volgograd, Publ. Al'yans, 2006. 256 p.

Conflict of interests: The authors declare no information of obvious and potential conflicts of interest related to the publication of this article.

Received: 22.12.2019

Accepted: 20.11.2020

Irina S. Dedova

Cand. Sci. (Geogr.), Associate Professor, Department of geography, geoecology and methods of teaching geography, Volgograd State Social and Pedagogical University, Volgograd, Russian Federation, ORCID:

https://orcid.org/0000-0002-2768-9421, e-mail itrofimova@yandex.ru

Tatyana N. Burul

Cand. Sci. (Geogr.), Associate Professor, Department of geography, geoecology and methods of teaching geography, Volgograd State Social and Pedagogical University, Volgograd, Russian Federation, ORCID:

https://orcid.org/0000-0002-6750-3919, e-mail busmit@mail.ru

Nadezhda P. Dyachenko

Cand. Sci. (Geogr.), Associate Professor, Department of geography, geoecology and methods of teaching geography, Volgograd State Social and Pedagogical University, Volgograd, Russian Federation, ORCID:

https://orcid.org/0000-0002-9576-0250, e-mail ms.npdyachenko@mail.ru 